\title{
DIFICULDADES DE APRENDIZAGEM RELACIONADAS À AQUISIÇÃO DA LEITURA E ESCRITA
}

BIANCHI, Thayse Barbosa Borges ${ }^{1}$

LOPES, Mario Marcos ${ }^{2}$

\author{
Recebido em: 2020.10 .30 \\ Aprovado em: 2021.02.09 \\ ISSUE DOI: $10.3738 / 1982.2278 .2897$
}

\begin{abstract}
RESUMO: O presente artigo tem como objetivo discutir as principais dificuldades de aprendizagem no processo de alfabetização (leitura e escrita) durante os anos iniciais do ensino fundamental e apontar estratégias que possam ser utilizadas para minimizar as deficiências neste processo. Dessa forma, a pesquisa servirá como material de apoio aos profissionais da área da educação que atuam nos anos iniciais do ensino fundamental, podendo auxiliar nas intervenções pedagógicas. Este artigo aponta os principais teóricos que discutem a temática e suas contribuições em relação às causas das dificuldades de aprendizagem no processo de aquisição da leitura e escrita e a importância da sua identificação e da intervenção no desenvolvimento do estudante. Para isso, realizou-se uma pesquisa de abordagem qualitativa, de objetivo exploratório, por meio de uma pesquisa bibliográfica, que embasa o estudo. Os resultados mostram que a escola, a família e o educador devem trabalhar em conjunto na busca de soluções diversificadas para contribuir ou minimizar essas dificuldades.
\end{abstract}

Palavras-Chave: Alfabetização. Intervenção pedagógica. Anos Iniciais.

\section{LEARNING DIFFICULTIES RELATED TO ACQUISITION OF READING AND WRITING}

SUMMARY: This article has the general objective of discussing the main learning difficulties in the literacy process (reading and writing) during the initial years of elementary education and to point out strategies that can be used to minimize the deficiencies in this process. In this way, the research will serve as support material for education professionals who work in the initial years of elementary education, and can assist in pedagogical interventions. This article points out the main theorists who discuss the theme and their contributions in relation to the causes of learning difficulties in the process of reading and writing acquisition and the importance of their identification and intervention in student development. For that, a research of qualitative approach, of exploratory objective, was carried through, through a bibliographical research, that bases the study. The results show that the school, the family and the educator must work together in the search for diversified solutions to contribute to or minimize these difficulties.

Keywords: Literacy. Pedagogical intervention. Early Years.

\section{INTRODUÇÃO}

A alfabetização é um processo desafiador nos anos iniciais da educação básica para os professores, pois envolve a aprendizagem da leitura e escrita. Assim, esse assunto tem sido destaque na preocupação dos educadores, pois mesmo com a variedade de métodos, muitas crianças concluem os primeiros anos sem aprender a ler e a escrever. No entanto, os alunos chegam à escola, cheios de expectativa e vontade de aprender, mas alguns enfrentam maiores dificuldades, visto que alguns fatores podem estar interferindo em seu processo de aprendizagem, como: a metodologia do professor, o desinteresse da família, questões emocionais, entre outros.

\footnotetext{
${ }^{1}$ Especialista em Psicopedagogia Institucional

${ }^{2}$ Centro Universitário Barão de Mauá. Faculdade de Educação São Luís. Secretaria de Estado da Educação Governo do Estado de São Paulo
} 
As dificuldades na leitura e escrita, muitas vezes, estão atreladas à falta de conhecimento dos educadores em como trabalhar essas dificuldades e quando elas não são trabalhadas podem gerar várias consequências durante o período escolar e/ou por toda a vida dos estudantes; como a repetência e o abandono da escola, impedindo que alcancem o mínimo de instrução. Dessa forma, é importante que essas dificuldades sejam identificadas pelos professores, visto que eles exercem papel fundamental em auxiliar os alunos no seu processo de aprendizagem.

Em um contexto social, o processo de aquisição e compreensão da língua escrita possibilita a inclusão e a participação da criança no mundo letrado, para isso é fundamental que ela reconheça o valor e a função da escrita, pois conforme Gomes $(2011$, p. 23) “[...] aprender a ler e escrever é muito mais de que adquirir habilidades básicas. É principalmente construir, obter e atribuir sentido e significado à aprendizagem".

Visando responder à questão deste estudo, tem-se o seguinte objetivo geral: analisar e discutir as principais dificuldades de aprendizagem relacionadas à leitura e à escrita durante o processo de alfabetização para aperfeiçoamento dos métodos pedagógicos a fím de amenizar as defasagens.

Para se chegar ao objetivo geral foram elaborados os objetivos específicos, sendo eles:

a) apresentar referencial teórico sobre o tema;

b) discorrer sobre os diferentes conceitos e causas das dificuldades de aprendizagem na leitura e escrita;

c) mostrar o papel do professor, a relação da família e escola no processo de aprendizagem;

d) apresentar sugestões que podem ajudar nas práticas pedagógicas.

Sendo assim, o artigo justifica-se por apresentar as principais causas das dificuldades no processo da leitura e da escrita e mostrar algumas soluções que podem ajudar os profissionais da área da educação com esse desafio, visto que elas estarão sempre presentes no ambiente escolar, mas quando confrontadas podem ser amenizadas ou resolvidas.

A escolha por esta temática baseou-se em inquietações dos profissionais (docentes), sobre tentar entender essas dificuldades que ocorrem em um dos processos mais importantes para as crianças e o que fazer para poder ajudá-las.

A metodologia utilizada para realizar essa pesquisa teve como base o método exploratório, pois conforme Gil (2010), esse tipo de pesquisa envolve levantamento bibliográfico, documental e estudo de caso, sendo que a sua principal finalidade é propiciar maior familiaridade com o problema, visando a torná-lo mais explícito ou a construir hipóteses. Em relação aos procedimentos técnicos, o método utilizado foi a pesquisa bibliográfica que segundo Gil (2010, p.

Nucleus, v.18, n.1, abr. 2021 
50), “[...] é desenvolvida a partir de material já elaborado, constituído principalmente de livros e artigos científicos". Dessa forma, buscou-se reunir e revisar a bibliografia sobre estudos de alguns teóricos, dentre eles: Ferreiro (1999), Weiss (2012), Gomes (2006), Chabanne (2006), Torres e Fernández (2001). Traçando um panorama sobre o assunto. Quanto à abordagem do problema, a pesquisa em questão é classificada como qualitativa, pois de acordo com Mascarenhas (2012), utilizamos esse tipo de pesquisa para descrever o objeto de estudo de forma mais profunda.

\title{
2 DIFICULDADES DE APRENDIZAGEM NA LEITURA E ESCRITA
}

Segundo Moojen e Costa (2006), os aspectos da aprendizagem são classificados em duas categorias: as dificuldades naturais ou secundárias e os transtornos. As dificuldades naturais são experimentadas por todos os indivíduos em algum momento da vida escolar, visto que são dificuldades transitórias e que tendem a desaparecer com um esforço maior do aluno ou com a ajuda de um professor particular. As secundárias são os transtornos com quadros neurológicos mais graves ou emocionais significativos. E os transtornos de aprendizagem que são de três tipos: “da leitura, da expressão escrita (ou soletração) e das habilidades matemáticas, que se manifestam em três níveis de gravidade: leve, moderado e grave”. Segundo Moojen e Costa (2006, p. 105) no nível grave, temos a dislexia, por exemplo.

Chabanne (2006, p. 16), explica que:

\begin{abstract}
A dificuldade escolar não deve ser considerada como um problema definitivo: é um momento da experiência, ou do trabalho escolar, que visa ao sucesso. Nesse aspecto, ela parece uma coisa comum e sem importância para todos os alunos que se dedicam a um objetivo escolar autêntico: todo exercício apresenta dificuldades, ou seja, sempre há um momento em que o aluno é posto à prova quanto à sua memória, sua inteligência, sua capacidade de interpretar um enunciado, de buscar soluções, de procurar novos caminhos e avaliar a eficácia de alguns deles, ou seja, de conviver com as dificuldades relativas e necessárias para alcançar o estágio definitivo: o sucesso.
\end{abstract}

A dificuldade então pode ser considerada como momentânea e se manifesta quando a pessoa encontra obstáculos durante sua trajetória em relação a um objetivo e a melhor forma de situar as dificuldades é analisar a história do indivíduo, pois conforme Chabanne (2006, p. 26) "as dificuldades podem ser a expressão de reações de proteção ou de defesa, provavelmente resultantes de traumatismos ou agressões. Elas podem ser reacionais". Além disso, para a pessoa que aprende o que interessa é o acontecimento e esse não deveria ser programado pelo professor, mas sim quando o aluno estiver pronto ou não para reconhecê-lo. Quando abordamos dificuldades escolares, podemos incluir vários tipos de dificuldades: as que são especificas do aluno, as que ele pode ter ao perceber que está com dificuldade e as que a escola cria. $\mathrm{O}$ autor 
também frisa que algumas dificuldades de aprendizagem podem estar relacionadas ao ritmo escolar, visto que temos o tempo escolar organizado pela instituição e o tempo vivenciado pelo aluno. Porém, deve ser levado em consideração o ritmo de cada aluno, visto que ele é o autor de sua aprendizagem.

Nesse sentido Valmaseda (2007) defende que o termo dificuldade está relacionado à ideia de desajuste que a criança apresenta comparada a outras da mesma idade.

$\mathrm{Na}$ abordagem psicopedagógica, Weiss (2012) conceitua fracasso escolar como resultado insatisfatório do aluno diante a um quesito da escola que pode ser entendida por diferentes perspectivas: a da sociedade: que envolve a cultura, as condições político-sociais e econômicas atuais, a estrutura social, as ideologias e as relações desses aspectos com a educação; a da escola: má qualidade de ensino, falta de estrutura e material, profissionais desqualificados, métodos tradicionais, pouca inovação na maneira de ensinar; a do aluno: condições internas de aprendizagem.

Nesse sentido Paz (1971 apud PAÍN, 1985), considera o problema de aprendizagem como um sintoma, visto que o não-aprender não configura um quadro permanente.

\subsection{Causas das dificuldades de aprendizagem}

Conforme Paín (1985), o diagnóstico de um problema de aprendizagem é constituído pelo significado e é necessário levar em consideração alguns fatores, como: fatores orgânicos, específicos, psicógenos e ambientais.

a) Fatores orgânicos: toda aprendizagem tem origem nos esquemas de ação desdobrados mediante o corpo. É fundamental a integridade anatômica e de funcionamento dos órgãos, bem como dos dispositivos que garantem sua coordenação no sistema nervoso central, visto que um sistema nervoso sadio se caracteriza no âmbito do comportamento, por seu ritmo, por sua plasticidade, seu equilíbrio.

b) Fatores específicos: determinados transtornos na área percepetivo-motora, geralmente na aprendizagem da linguagem, impede a construção de imagens claras de fonemas, sílabas e palavras, a inaptidão gráfica e sintática, dificuldade na análise e síntese dos símbolos.

c) Fatores psicógenos: envolve duas possibilidades para não aprendizagem, à primeira vista como um sintoma e a segunda uma retratação intelectual do ego. Essa retração segundo Freud (1925 apud PAÍN, 1985) aparece em três momentos: a primeira, quando há sexualização dos órgãos; a segunda quando se evita o êxito ou a compulsão ao fracasso; e a terceira quando o ego está envolvido em outra tarefa psíquica que esgota a energia que existe. Ademais, a retração do ego também surge como singularidade do fenômeno neurótico, que pode causar duas reações:

Nucleus, v.18, n.1, abr. 2021 
uma reage ao impulso de repetição do momento de trauma e, a outra, evita. Trata-se de meios de defesa para lidar com a angústia.

d) Fatores ambientais: trata-se do meio ambiente material do sujeito, que tipo e como foram as oportunidades que esse meio lhe proporcionou, quantos estímulos o sujeito recebeu em seu campo de aprendizagem habitual.

Para o Weiss (2012), o fracasso escolar é ocasionado por uma junção de causas interligadas que impossibilitam o aluno de ter um bom desempenho na escola. Por exemplo, a imposição de que a criança formalize a escrita obedecendo as regras em determinado prazo, pode ser uma questão relacionada à cobrança escolar de avaliar apenas o produto. A maneira como for aplicada, pode gerar dificuldades na escrita e leitura nessa etapa e posteriormente, não se tratando de uma questão de problema pessoa, mas de método escolar. Além disso, não respeitar o ritmo de desenvolvimento da criança na leitura e escrita pode gerar dificuldades acumulativas que podem paralisar seu processo de alfabetização. A autora ressalta que a origem do fracasso, geralmente está na má condução do processo e que toda escola deve estar organizada na busca do melhor ensino, outras falhas estão na quantidade de informações transmitidas e a forma como são avaliadas. Isso gera ansiedade incontrolável no aluno que podem desorganizar sua conduta por não suportar tanta ansiedade.

Oliveira e Monteiro (2009) identificaram outros fatores que interferem na alfabetização nos anos iniciais do Ensino Fundamental, dentre os quais destacamos: a) a necessidade de mais tempo para alunos com dificuldades atinjam os objetivos; b) falta de disciplina, relacionada em parte à falta de envolvimento em algumas das atividades propostas; c) baixa autoestima, gerando necessidade de reforço constante nas atividades desenvolvidas; d) faltas, prejudicando o aspecto pedagógico; e) problemas de saúde; f) não reconhecimento da leitura e da escrita, entre outros.

Monteiro (2008) complementa que os professores enfrentam dificuldades na relação entre a teoria e prática e que a falta de formação de alguns relacionados a fundamentos linguísticos e psicopedagógicos atrapalham a sua ação pedagógica.

Para Soares (2017, p. 97) “as diferenças estruturais entre o dialeto padrão e os dialetos não padrão têm sido apontadas como causa do fracasso escolar das crianças pertencentes às camadas populares, falantes daquele dialeto não padrão". Dessa forma, classes sociais diferentes controlam algumas funções da língua, em detrimento de outras. Isso acontece, pois, as crianças das classes favorecidas têm mais oportunidades dentro do seu contexto cultural com livros, ouvem histórias, no entanto, a maioria das crianças das camadas populares não tem essas mesmas vivências e entram em conflito entre as suposições sobre as funções da escrita e o que a escola trabalha. 
Soares (2017) explica que uma das causas do fracasso escolar pode estar ligada ao surgimento da ideia de que alfabetizar deve estar mais voltado para o conceito de letramento e assim as escolas brasileiras se atrapalharam com o que seria alfabetizar.

Em relação à escrita, Garcia (1998) afirma que o atraso na escrita pode ser pela falta de escolarização adequada, pouca motivação ou baixo intelecto no ambiente familiar. Ademais o contexto social que a criança está inserida pode refletir na sua produção escrita, visto que a criança que vive num ambiente estimulador pode dar mais importância à escrita. Outro motivo que pode causar o atraso é no processo motor com a mistura de letras maiúsculas e minúsculas, de vários tipos de escrita, adições ou exclusões de letras, desenhos de letras erradas, grafemas grandes ou muito pequenos, desigualdade entre as letras, linhas inclinadas, espaços enormes, ajuntamento de letras e palavras e não respeito às margens.

Segundo Micotti (2009), dificilmente todas as crianças de uma turma conseguem se alfabetizam no primeiro ano, porém, a maioria dos professores do próximo ano, não leva isso em consideração e a criança pode não ter outras oportunidades para aprender a ler. Dessa forma, espera que as crianças já tenham adquiridos conhecimentos básicos na leitura e na escrita, mas pode ser que na serie anterior, essas habilidades não foram bem trabalhadas. Além disso, a autora também traz outra abordagem para os problemas na alfabetização; a forma tradicional de ensino. Micotti (2009, p. 33) destaca que "os professores, em geral, foram alfabetizados e aprenderam a alfabetizar mediante cópia, ditados e leitura em voz alta, com material estruturado para facilitar a associação entre elementos da língua oral e escrita". Na didática tradicional, o educador mostra os elementos do código escrito e os seus correspondentes sonoros, ensina a juntar as sílabas para formar palavras e cobra respostas repetitivas, sem discutir outras respostas. Ao utilizar essa didática não se leva em consideração que processo da escrita não acontece pra todos ao mesmo tempo e nem ao contato com o primeiro texto e o professor acaba fazendo interferências inadequadas, sem respeitar o desenvolvimento de cada criança.

\subsection{Visões da escola sobre as dificuldades de aprendizagem}

Segundo Gomes (2011), é possível perceber que a escola cria diferentes justificativas para as dificuldades de aprendizagem, as mais frequentes são:

a) Famílias desestruturadas, a culpa pelo fracasso recai sobre as famílias das crianças, podendo ser a ausência da mãe e com isso a falta de assistência acompanhamento escolar.

b) Dificuldades econômicas, quando as crianças têm nível sociocultural baixo e moram em lugares precários.

Nucleus, v.18, n.1, abr. 2021 
c) Problemas cognitivos ou intelectuais, quando os alunos apresentam lentidão, desinteresse, não acompanham a turma, isso indicaria a falta de habilidades intelectuais.

d) Problemas orgânicos, busca se nos alunos características que possam qualifica-los como portadores de algum problema de ordem física e/ou neurológica.

A escola cria essas justificativas como suporte para justificar os seus prognósticos e assim o aluno passa a receber tratamento diferenciado por meio de atividades paralelas, como trabalhos manuais, ou atividades com um grau menor de dificuldade, além de punições e castigos, como utilização de apelidos, comentários. Dessa forma, a escola atribui que o problema está no aluno e que só eles podem resolver, fazendo com que ele se sinta culpado pelo fracasso. À medida que isso acontece, os alunos mesmo com interesse em aprender e vontade de realizar outras atividades, também demonstram tédio pelo cotidiano da sala de aula, visto que são vistas por eles como improdutivas e sem sentido. (GOMES, 2011)

Para Ferreiro e Teberosky (1999), a escola dirige-se a quem já sabe e o método está voltado para aqueles que já percorreram, sozinhos, um longo e prévio caminho. Assim, o sucesso da aprendizagem depende das condições de como a criança está no momento de receber o ensino. Somente as que estão bem avançadas de conceitualização tiram proveito dessa forma tradicional de ensino e conseguem aprender o que o professor quer ensinar-lhes. As demais fracassam e são acusadas de incapazes de aprender ou de dificuldades de aprendizagem. Com isso, nega-se que toda aprendizagem supõe um processo e não se respeita que existem diferenças em relação ao momento de desenvolvimento conceitual em que se situam, visto que nenhum individuo parte de zero ao entrar na escola de ensino fundamental, seja as crianças de classe baixa que são mais desfavorecidas.

Ferreiro e Teberosky (1999, p. 291) argumentam que:

Aos 6 anos, as crianças "sabem" muitas coisas sobre a escrita e resolveram sozinhas numerosos problemas para compreender as regras da representação escrita. Talvez não estejam resolvidos todos os problemas, como a escola o espera; porém o caminho se iniciou. Claro que é um caminho que difere fundamentalmente do processo suposto pela escola. E difere porque os problemas e as formas de resolução são - como demonstramos o fruto de um grande esforço cognitivo.

O que acontece é que a escola considera que é por meio de técnica, de exercícios adequados que se supera o conflito da língua escrita. O segmento clássico leitura mecânica, compreensiva, expressiva para a leitura e o aperfeiçoamento na cópia gráfica presume que o segredo da escrita está em criar sons e reproduzir formas. (FERREIRO; TEBEROSKY, 1999)

\subsection{O processo de aprendizagem da leitura e escrita}

O problema de aprendizagem da leitura e escrita tem sido tratado pelos educadores como uma questão de métodos, em que se busca o método mais eficaz. Dentre eles estão os métodos 
sintéticos e os métodos analíticos. O primeiro faz correspondência entre o oral e escrito, entre som e grafia e consiste em ir das partes mínimas (letras) ao todo. O segundo parte de unidades maiores, como o texto. Posteriormente, com a influência da linguística desenvolveu-se o método fonético, que parte do oral, sendo que o fonema é a unidade mínima de som da fala. (FERREIRO; TEBEROSKY, 1999).

O processo de aquisição da leitura e escrita começa antes do que se pensa, antes mesmo de entrar na escola a criança tem contato com materiais escritos, em casa, na rua e outros lugares que a criança frequenta. Para entender a escrita a criança pré-escolar raciocina com inteligência, faz boas hipóteses a respeito de sistemas de escrita, supera conflitos, busca regularidades e atribui significado. Essas hipóteses ocorrem em todas as crianças e progridem desde a fase pré-silábica, em que ainda não existe intuito de representar por meio da escrita os fatores sonoros da fala até chegar ao nível alfabético em que a criança associa sons falados a letras escritas. Toda criança passa por quatro fases até estar alfabetizada: pré-silábica: não existe intuito de representar por meio da escrita os fatores sonoros da fala; silábica: percebe a letra a sua maneira, imputando valor de cada sílaba a cada uma; silábico alfabético: usa a lógica anterior com a identificação de algumas sílabas; alfabética: apodera-se do valor das letras e sílabas. Dessa forma, percebe-se que o processo de aprendizagem da escrita ocorre de forma gradual, por meio de etapas, até que a criança consiga domine o código linguístico (FERREIRO; TEBEROSKY, 1999).

No entanto, a coerência lógica que ela exige de si mesma desaparece diante das exigências do docente. Para Ferreiro e Teberosky (1999, p. 290) “entre as propostas metodológicas e as concepções infantis há uma distância que pode medir-se em termos do que a escola ensina e do que a criança aprende". Ou seja, nem sempre coincide o que a escola pretende ensinar com o que a criança consegue aprender.

Assim, o docente tentando descobrir os mistérios do código alfabético procede do simples ao complexo, segundo uma definição criada por ele, tentando simplificar o sistema alfabético. Supõe-se que todas as crianças estão prontas para aprender o código desde que o professor possa ajudá-las. Essa ajuda seria transmitir-lhe o equivalente sonoro das letras e treiná-las na realização gráfica da cópia. Porém, a criança aprende á medida que vai se apropriando do objeto, por meio de uma lenta construção de critérios que lhe ajude a compreendê-lo, é somente no fim do processo que os critérios da criança coincidem com os do professor (FERREIRO; TEBEROSKY, 1999).

Ademais, Silva (2010) salienta a importância da capacidade de imaginação da criança no seu desenvolvimento linguístico diante da relação inventiva que ela tem com a linguagem. 
Gomes (2011) realizou um estudo sobre a produção de alunos considerados como bons e maus alunos pela escola referente à leitura e à escrita e traz importantes considerações. Em relação aos aspectos escolares, ele observou que no processo ensino e aprendizagem, a escrita é transformada em mera cópia, não proporcionando as crianças fazerem relação de sua aprendizagem com a escrita. A aprendizagem ocorre de maneira descontextualizada com ênfase na memorização de letras, sílabas, frases e textos. No entanto, todas as crianças demonstraram capacidade de reflexão sobre a língua escrita por meio de variações ortográficas, mas que pela escola são consideradas como o que os alunos não aprenderam. Além disso, o autor afirma que tanto os alunos considerados como bons ou maus demonstraram vontade e capacidade de aprender e se não avançaram mais foi por falta de condições necessárias e suficientes por parte da escola e de suas famílias. Para ele, aprender a ler e a escrever é muito mais do que adquirir habilidades básicas, é construir, obter e atribuir sentido e significado à aprendizagem.

\subsubsection{Principais problemas de aprendizagem}

\subsubsection{Disgrafia}

Considera-se uma pessoa com disgrafia quando, culturalmente, ela não consegue produzir uma escrita aceitável, mesmo que tenha nível intelectual e instrução adequada, sem déficits sensoriais e lesões neurológicas específicas. As principais causas da disgrafia são a sequencialização, gerando dificuldades na sequencia do processamento da informação recebida e na sua forma de organização e processamento. Nessa última, as dificuldades podem ser de origem auditiva e afetar a aprendizagem e a compreensão da linguagem; a aprendizagem verbal; e de origem visual que afeta o processo visual da informação; aprendizagem não verbal. Também se pode perceber, distúrbios de motricidade ampla e especialmente fina, além de distúrbios de coordenação visiomotora, a deficiência organização espaço-temporal, os problemas de lateralidade e direcionalidade. (NOGUEIRA, 2012)

Torres \& Fernández (2001) atribuem três tipos as causas da disgrafia: maturativas, carateriais e pedagógicas. As primeiras geram nas crianças perturbações de lateralidade e de eficiência psicomotora (motricidade, equilíbrio). Elas são desajeitadas do ponto de vista motor (geralmente tem idade motora inferior à idade cronológica) e apresentam uma escrita irregular ao nível da pressão, velocidade e traçado, além de desordem na organização perceptivo-motora, estruturação/orientação espacial e interiorização do esquema corporal. As causas carateriais, estão relacionadas a fatores de personalidade, que podem, consequentemente, definir o aspecto do grafismo (estável/instável, lento/rápido), e também a fatores psicoafetivos, visto que o sujeito retrata na escrita o seu estado e tensão emocionais. E as causas pedagógicas podem estar associadas, por exemplo, com uma educação rígida e inflexível, com uma alteração inadequada 
de letra de imprensa para letra manuscrita e/ou uma ênfase exagerada na qualidade ou agilidade da escrita.

Cinel (2003) aponta cinco grupos de causas da disgrafia: - Distúrbios na motricidade ampla e fina, relacionados com a ausência de coordenação entre a intenção do que a criança quer fazer e o que realiza (perturbações no domínio do corpo); - Distúrbios na coordenação visomotora, relacionada à dificuldade no acompanhamento visual do movimento dos membros superiores e/ou inferiores; - Deficiência na organização espaço-temporal (direita/esquerda, frente/atrás/lado e antes/depois); - Dificuldade na lateralidade e direcionalidade; - Falhas pedagógicas, associadas com processo de ensino inadequado, soluções inapropriadas pelos docentes ou falta de conhecimento.

\subsubsection{Disortografia}

Conforme Pereira (2009, p. 9), a disortografia é:

\footnotetext{
Perturbação que afeta as aptidões da escrita e que se traduz por dificuldades persistentes e recorrentes na capacidade da criança em compor textos escritos. As dificuldades centram-se na organização, estruturação e composição de textos escritos; a construção frásica é pobre e geralmente curta, observa-se a presença de múltiplos erros ortográficos e [por vezes] má qualidade gráfica.
}

Segundo Nogueira (2012), a disortografia acontece pelas trocas ortográficas e confusão com as letras, trata-se da incapacidade de transcrever corretamente a linguagem oral. É importante ressaltar que essas trocas são normais nas séries iniciais do ensino fundamental, visto que a relação entre a palavra impressa e os sons não está totalmente dominado. Os psicopedagogos e professores devem buscar o desenvolvimento das habilidades de escrita com atividades de soletração, consciência fonológica, ortográfica e morfológica e composições.

Para Torres \& Fernández (2001), as causas da disortografia estão relacionadas com aspetos perceptivos, intelectuais, linguísticos, afetivo-emocionais e pedagógicos. As causas de tipo perceptivo referem-se à falta de percepção, na memória visual e auditiva e/ou a nível espaçotemporal, que influencia na correta orientação das letras e na distinção de grafemas com traços parecidos, por exemplo. Em relação às causas de tipo intelectual, referem-se a falta de maturidade intelectual; pouco nível de inteligência geral que pode resultar em uma escrita errada, pois a criança não domina as operações de caráter lógico-intelectual fundamentais ao conhecimento e diferenciação dos variados elementos sonoros. Nos aspectos linguísticos as causas apontadas são problemas de linguagem (pronúncia/articulação) e/ou deficiente conhecimento e uso do vocabulário (código restrito). Referente às de tipo afetivo-emocional, as causas são baixos níveis de motivação e atenção, que poderão fazer com que a criança cometa erros ortográficos, embora 
conheça a ortografia das palavras. Por último, as causas aspectos pedagógicos estão direcionados aos métodos de ensino inadequados: por exemplo, quando o professor fazer uso frequente do ditado, desajustado às necessidades individuais dos alunos e sem levar em consideração os seus ritmos de aprendizagem.

\subsubsection{Dislexia}

A Associação Internacional de Dislexia definiu dislexia como:

[...] uma incapacidade específica de aprendizagem, de origem neurobiológica. É caracterizada por dificuldades na correção e/ou fluência na leitura de palavras e por baixa competência leitora e ortográfica. Estas dificuldades resultam de um déficit fonológico, inesperado, em relação às outras capacidades cognitivas e às condições educativas. Secundariamente podem surgir dificuldades de compreensão leitora, experiência de leitura reduzida que pode impedir o desenvolvimento do vocabulário e dos conhecimentos gerais. (ASSOCIAÇÃO INTERNACIONAL DE DISLEXIA, 2003 apud InfoCEEDI, 2011, p. 1).

Nesse sentido, o Instituto ABCD (2020) explica que existem diferentes níveis de dislexia, podendo ser casos considerados leves até severos. Nos casos leves, acontecem erros na escrita, mas é possível compreender os textos após algumas leituras, já em casos severos a dificuldade pode ser maior começando no processo de alfabetização por atrapalhar o desenvolvimento da leitura, escrita e compreensão.

Fonseca (2009) conceitua dislexia como uma dificuldade de aprendizagem inesperada, não se trata de uma doença, nem de uma incapacidade ou QI baixo. A dislexia pode aparecer durante a vida do indivíduo mesmo com oportunidades de aprendizagem apropriada. As crianças disléxicas demoram mais tempo para aprender a ler, independentemente de a sua inteligência ser normal e das circunstâncias de ensino adequadas.

Conforme a Associação Brasileira de Dislexia (2020), alguns sinais são apresentados tanto na pré-escola como na idade escolar. Na pré-escola: dispersão, pouco desenvolvimento da atenção, atraso no desenvolvimento da fala e linguagem, dificuldade com rimas, canções e quebra cabeça, pouco desenvolvimento da coordenação motora e desinteresse por livros escritos. Na idade escolar: dificuldade para aprender a ler e escrever falta de atenção, dificuldade em copiar da lousa e de livros, falta de organização com seus materiais, dificuldade na coordenação motora fina e grossa, vocabulário insuficiente, dificuldade no manuseio de mapas, dicionários e lista telefônica.

Para Nogueira (2012) é o comprometimento acentuado no desenvolvimento nas habilidades de reconhecimento das palavras e da compreensão da leitura. Não há cura plena para esse transtorno, mas por meio de adaptações pedagógicas é possível melhoras gradativas. 


\section{RELAÇÃO DA ESCOLA COM A FAMÍLIA NO PROCESSO DE ALFABETIZAÇÃO}

Segundo Berberian e Bergamo (2009), a escola é decisiva na formação e circulação de hábitos, valores e costumes, dessa forma desempenha função fundamental na vida das pessoas. Ademais, a escola é uma das principais organizações da utilização e valores da linguagem oral e escrita.

Nesta perspectiva, Goulart (2016) afirma que os anos iniciais do ensino fundamental são um dos mais importantes para as crianças, visto que são dedicados diretamente ao ensino da leitura e da escrita. Assim, é um dos momentos que a escola mais necessita do auxilio das famílias para que ajudem seus filhos em casa com as atividades de leitura e escrita. A escola conta com esse auxilio, visto que considera tarefas fáceis que qualquer adulto alfabetizado consegue ajudá-las. No entanto, nem sempre os pais conseguem ou tem o conhecimento necessário para ajudá-los e a escola não deve responsabilizar as famílias pela não aprendizagem das crianças. A família pode participar das atividades escolares e dialogar com os profissionais da escola sobre as direções da educação almejada para os filhos, mas não se devem confundir os papeis, a responsabilidade da educação escolar é dos profissionais de educação, bem como garantir o aprendizado das crianças.

Ademais, o artigo 12 da Lei de Diretrizes e Base da Educação Nacional (LDB), indica que os estabelecimentos de ensino devem estabelecer vínculos com as famílias e a comunidade, a fim de promover integração da sociedade com a escola. Porém, conforme defende a autora Goulart (2016), é necessário que os profissionais de educação tenham cuidado com a falta de clareza dessa participação, pois pode gerar visões estereotipadas e tendenciosas sobre os tipos dos pais. Sendo que os pais que vão mais frequentemente à escola, são vistos como pais chatos e os pais que não vão à escola ou aparecem poucas vezes, são vistos como omissos. Isso indica que quando não se sabe o que se espera das famílias, raramente se cria uma imagem positiva dessa relação.

Portanto, conforme Rief e Heimburge (2000, p. 127) "os pais devem estar dispostos a partilhar informações com os professores, assim como devem tentar saber como podem ajudar e apoiar o professor de todas as maneiras possíveis". E os professorem também precisar estabelecer essa relação de cooperação com os pais.

Além disso, Campos (1997, p. 152) explica que "uma pessoa motivada para aprender constrói o conhecimento mais prontamente, do que uma sem motivação". Então, para que o processo da leitura aconteça é necessário que a criança receba incentivos por partes dos responsáveis pela sua aprendizagem a fim de que a leitura e a escrita proporcione ao indivíduo 
um universo amplo e ilimitado e que por meio dessas habilidades possa aperfeiçoar, tornando-se um indivíduo que corresponda com as necessidades do meio (FERNÁNDEZ, 2001).

\subsection{A importância do professor no processo de aprendizagem}

Conforme Goulart (2016, p. 57) "entrar no mundo da escrita abre muitas janelas para crianças, jovens e adultos. Representa uma nova forma de ser reconhecido e de participar socialmente, de aprender sobre temas que compõem a cultura escrita de várias maneiras”. A escrita está no mundo e de maneira geral todos sabem sobre a escrita e seu valor social, até sem frequentar a escola, visto que está tudo ligado à experiência de viver o dia a dia, assistir à televisão, escutar e participar de conversas. Sendo assim, ao ingressar na escola, as crianças já trazem consigo conhecimento sobre a escrita que se espalha nos espaços sociais e desejam saber mais. É por meio do trabalho continuo com a leitura e escrita de forma diversificada, as crianças ampliam o conhecimento sobre o mundo da escrita e o sistema alfabético.

Nessa perspectiva, Pinto e Menezes (2013), defende que o educador deve realizar um projeto pedagógico com experienciais significativas, pois a alfabetização não pode ser apenas para nomear as coisas, visto que a criança recebe as informações, elabora suas próprias hipóteses e reestabelece no meio social.

O principal para que aconteça essa aprendizagem é a fala, a conversa, a interação entre a professora e as crianças e entre crianças com crianças. O diálogo é fundamental para que a escrita seja aprendida e praticada, diariamente, com atividades desafiadoras e significativas. Dar oportunidade as crianças de atividades orais de leitura e de escrita e de materiais escritos diferentes, animam-nas a escreverem do jeito que conseguem. O mais importante nesse processo é acreditar que todas as crianças são capazes de aprender, umas mais lentamente, outras se distraem com mais facilidade e outras ainda não demonstram muita pressa em aprender (GOULART, 2016)

Nesse sentido, Leite (2011) destaca a importância da relação afetiva em sala de aula para fazer a intervenção pedagógica, ele mostra que o processo que forma o leitor é desenvolvido por meio de um movimento social, em que é fundamental a intervenção do outro.

A professora precisa estar sempre atenta ao movimento da turma para escutar as crianças, responder a suas perguntas, desafiá-las, fazer comparações, situações-problema, sempre levando em consideração o seu tempo e seu modo de aprender. As comprovações de que estão progredindo no conhecimento vêm de diversas maneiras, como explica Goulart (2016, p.59):

Pode ser pela própria observação de crianças que já conseguem ler aos pouquinhos palavras escritas em que se destacam; crianças que começam a falar silabadamente, procurando descobrir a letra que devem utilizar; crianças que dão ênfase a aspectos sonoros mais específicos, próximos de fonemas, aprofundando a decomposição sonora 
das palavras; crianças conversando sobre como representar as palavras por escrito; crianças que estabelecem relações de palavras desconhecidas com palavras conhecidas, aproximando-as para dar solução a suas necessidades de escrita.

Ensinar a ler e a escrever compreende estimular as crianças a buscarem pistas nos materiais concretos e suportes de textos que ajudam a dar significado aos textos. Ademais é necessário planejar momentos para dar atenção individual a cada criança, para que o professor possa além de observar o que a criança sabe como leem e escrevem, mas também observar outras questões específicas. Algumas crianças têm melhor desempenho quando trabalham em grupo, conseguem aproveitar para fazerem trocas, no entanto, outras necessitam de atenção individualizada, ás vezes, e pode fazer uma diferença. Para isso, o professor deve pensar na sala de aula como um espaço dinâmico, proporcionar aos alunos que troquem de lugar e que os que são generosos e tem maior facilidade ajudem os colegas. Assim, ele consegue fazer mais intervenções durante as atividades, visto que o clima de cooperação e coleguismo depende do modo como a professora trata as diferenças entre as crianças (GOULART, 2016).

É fundamental que os educadores compreendam que cada aluno tem o seu estágio de desenvolvimento na leitura e na escrita e assim surgirão diferentes tipos de dificuldades. Cabe ao educador detectar esta fase e fazer uma interpretação diagnóstica sem prejudicar o aluno, é nesse momento que o professor deve utilizar diversas formas de avaliações que favoreça sua prática (FRANCHI, 2002).

No entanto, é importante levar em consideração conforme Weiss (2012, pág.21) que "Professores em escolas desestruturadas, sem apoio material e pedagógico, desqualificados pela sociedade, pelas famílias, pelos alunos não podem ocupar bem o lugar de quem ensina tornando o conhecimento desejável pelo o aluno". Assim, é importante que o professor competente e valorizado descubra a vontade de ensinar para que desperte no aluno a vontade de aprender.

\subsection{Estratégias para as práticas pedagógicas}

Conforme Goulart (2016), desde a educação infantil, é necessário que o professor conheça as crianças por meio de rodinhas, de entrevistas coletivas, desenhos, fazer um álbum da turma, uma lista de nomes, um calendário e ter materiais disponíveis na sala, como: letras móveis, revistas, jornais. Ademais, o professor deve selecionar textos bons e diversificados que atraia as crianças e planejar atividades por meio de exercícios, jogos e brincadeiras que promovam a inteligência infantil e também despertem a sensibilidade das crianças colaborando para fortalecêlas como pessoas. 
Furtado (2012, p. 58) complementa “[...] que os jogos trazem benefícios, [...] desenvolvem a memória, atenção, observação, raciocínio, criatividade e contribuem favorecendo a desinibição".

Negrine (1994, p. 19) esclarece que:

As contribuições do jogo no desenvolvimento integral indicam que ele contribui poderosamente no desenvolvimento global da criança e que todas as dimensões do jogo estão intrinsecamente vinculadas: a inteligência, a afetividade, a motricidade e a sociabilidade são inseparáveis, sendo que a afetividade constitui a energia necessária para a progressão psíquica.

Micotti (2009) sugere algumas ações que podem ajudar:

- Envolver os alunos e fazer com que eles participem das atividades;

- Dar oportunidades de aprendizagem a todos os alunos;

- Assegurar o desenvolvimento de conhecimentos básicos de leitura e escrita desde o início do ensino fundamental;

- Utilizar estratégias para dar continuidade do processo de aprendizagem;

- Trabalhar por meio das experiências vivenciadas pelo aluno;

- Vincular a educação infantil com o ensino fundamental.

Além disso, Micotti (2009, p. 40) propõe que a escola trabalhe por meio de projetos, visto que:

\begin{abstract}
As vivências orientadas pela pedagogia dos projetos, e a cooperação entre professores e alunos no desenvolvimento do trabalho escolar ajudam a criança a situar-se no dia a dia em sala de aula e, sobretudo a elaborar um sentido para sua vida escolar e para o aprendizado da leitura da escrita. $\mathrm{O}$ ensino assim organizado propicia aos alunos o desenvolvimento: da percepção global dos objetivos visados pelo trabalho que é realizado na escola; da organização adequada de atividades para a consecução dos objetos propostos; a consideração dos pontos de vista de pessoas; a construção do contato com a realidade na interação social; da autonomia (entendendo que uma pessoa pode ajudar, mas ninguém pode percorrer o caminho no lugar do outro; da confiança em si); do saber avaliar-se.
\end{abstract}

Dessa forma, ao utilizar projetos, a criança pode usar textos de formas variadas, ampliando sua visão sobre a escrita e participando ativamente do processo como escritora e leitora. A autora em seus estudos apresenta que algumas professoras já têm utilizado desta prática e têm surgido bons resultados. Conforme o projeto desenvolvido as crianças tinham que se comunicar com outras pessoas fora da escola, tendo a oportunidade de compreender a verdadeira função da escrita. No projeto, foram construídos cartazes, dicionário ilustrado para registro de alguma sílaba ou palavra. Na sala também havia espaços com atividades para os alunos pesquisarem quando precisassem. Outro aspecto importante é que muitas atividades foram desenvolvidas em grupo para enfatizar a vida cooperativa. Para atividades de produção textual, o 
professor levava os alunos primeiramente a uma reflexão sobre qual o tipo de texto usar para a situação, por exemplo, se os alunos queriam ir ao zoológico, necessitavam de uma autorização da direção da escola. Nesse momento a professora estimula os alunos a pensar nas características desse texto, como: destinatário, tipo de linguagem, entre outros. Assim, o aluno constrói seu aprendizado por meio de suas próprias hipóteses, usa ferramentas dispostas na sala como apoio, apropria-se do código da escrita em situações cotidianas e principalmente participa como sujeito ativo da aprendizagem (MICOTTI, 2009).

Cagliari (2009) também sugere algumas atividades que podem ser utilizadas pelo professor no processo de alfabetização, como criar um código: os alunos podem criar seus sistemas de escrita utilizando pictogramas, escrever histórias e bilhetes, podem inventar desenhos que representam palavras e recortar figuras de objetos, animais, pessoas, dispô-la em colunas e ao seu lado os desenhos respectivos às palavras, e após podem utilizar disso para escrever usando o código criado. Após a atividade, o educador pode fazer uma reflexão com os alunos a respeito de como o uso único de um sistema de escrita facilita a comunicação na sociedade. Para trabalhar unidades de fala menores que as palavras podem ser usadas a técnica rébus, em que se representa palavras ou frases por meio de desenhos ou sinais de acordo com a analogia que se quer fazer entender. Esse método de escrita permite mostrar aos alunos que a escrita pode ser baseada no significado das palavras ou nos sons que elas têm.

Para ajudar crianças disléxicas, Torres e Fernández (2001) sugere como recurso, uma terapia multissensorial, esse método combinam o uso da visão, audição e tato para auxiliar a criança a ler e soletrar de maneira correta as palavras. Além disso, também é necessário trabalhar o psicomotor, perceptivo motor e psicolinguístico. O Instituto ABCD (2020) complementa que o professor pode fazer uma avaliação adaptada ao aluno que tenha dislexia de maneira que permita mostrar o que ele aprendeu.

Em relação a alunos com disortografia o importante é usar uma variedade de técnicas que levem em conta não somente a correção dos erros ortográficos, mas também a percepção auditiva, visual e espaciotemporal, bem como a memória auditiva e visual. Torres e Fernández (2001) salientam duas áreas importantes na reeducação da disortografia: a intervenção sobre os fatores ligados ao fracasso ortográfico e a correção dos erros ortográficos específicos. É importante, também, que se diferenciem os erros de ortografia das falhas na compreensão e, consequentemente, da possibilidade de elaboração de respostas. No momento da avaliação, é necessário que o educador disponibilize um tempo maior para que o aluno responda às questões e/ou verificar se ele compreendeu os enunciados das questões; incentivar a expressão oral também poderá ser uma boa tática.

Nucleus, v.18, n.1, abr. 2021 
Torres e Fernández (2001) sugerem ainda que para alunos com disgrafia que o professor utilize técnicas de relaxamento global e segmentar, pois podem auxiliar a criança a reduzir os índices de ansiedade, estresse, frustração e também baixa autoestima, que estão presentes nas crianças com esse problema.

\section{CONSIDERAÇÕES FINAIS}

De acordo com as referidas abordagens é possível ver que existem divergências entre os autores no que diz respeito ao conceito de dificuldades de aprendizagem na leitura e escrita, visto a complexidade do assunto, pois aprender a ler e a escrever não é um processo simples e para algumas crianças pode ser mais demorado, porém o método de ensino na maioria das escolas resume-se que todas aprendam no mesmo ritmo, e quando isso não acontece, podem ser rotuladas como crianças com problemas na aprendizagem.

Outro ponto importante, é que as dificuldades de aprendizagem podem ser desencadeadas por diversos fatores, como: o ambiente que a criança vive, o seu estado emocional, profissionais desqualificados, contexto cultural, entre outros. Entretanto, dificuldades fazem parte do processo de aprendizagem e elas não devem ser superdimensionadas pelos pais e educadores que devem levar em consideração a individualidade de cada aluno e que não existe apenas um caminho para o sucesso.

Ademais, é fundamental que a escola estabeleça parceria com a família, mas sem cobranças excessivas, pois nem sempre a família sabe como ajudar, embora tenha vontade para isso. Quando essa relação não é estabelecida, o processo pode ser ainda mais difícil e ambos acabarem com suas expectativas não atendidas.

Nesse sentido, o papel do educador, principalmente nos anos iniciais do ensino fundamental, é de extrema importância, pois a maioria das dificuldades pode ser resolvida na sala de aula, desde que a criança receba acompanhamento pedagógico adequado às suas necessidades. Para isso, é necessário que o educador tenha conhecimento para identificar, o mais breve possível, os diferentes tipos de dificuldades na leitura e escrita e busque estratégias diversificadas para combatê-las.

Dentre as estratégias que o professor pode utilizar para auxiliar os alunos com dificuldades estão um atendimento mais individualizado, atividades lúdicas, uso da tecnologia, atividades em grupo, avaliação adaptada, trabalhar por meio de projetos, e atividades significativas no cotidiano da criança, sempre valorizando suas conquistas.

Por fim, é essencial que a escola promova a alfabetização em confluência com o mundo vivido pela criança, respeitando as suas peculiaridades, as suas brincadeiras, os seus desejos pessoais e principalmente, o seu jeito e tempo de aprender. É por meio dessa perspectiva que é 
possível promover o desenvolvimento e consequentemente o processo de alfabetização da criança.

\section{REFERÊNCIAS}

ASSOCIAÇÃO BRASILEIRA DE DISLEXIA. O que é dislexia. Disponível em: http://www.dislexia.org.br/o-que-e-dislexia/. Acesso em: 21 abr. 2020.

BERBERIAN, A. P.; BERGAMO, A. Psicogênese das linguagens oral e escrita: subsídios para a alfabetização e letramento. Curitiba: IESDE Brasil, 2009.

CAGLIARI, L. C. Alfabetizando sem o bá-bé-bi-bó-bu. São Paulo: Scipione, 2009.

CAMPOS, D. M. de S. Psicologia da aprendizagem. 26.ed. Petrópolis, RJ: Vozes, 1997.

BRASIL. Lei n. 9394 de 20 de dezembro de 1996. Estabelece as Diretrizes e Base da Educação Nacional. Disponível em: http://www.planalto.gov.br/ccivil_03/leis/L9394.htm. Acesso em: 14 nov. 2019.

CHABANNE, J.-L. Dificuldades de aprendizagem: um enfoque inovador do ensino escolar. São Paulo: Ática, 2006.

CINEL, N. C. B. Disgrafia - Prováveis causas dos distúrbios e estratégias para a correção da escrita. Porto Alegre: Revista do Professor, 2003.

FERNÁNDEZ, A. Os idiomas do aprendente. Porto Alegre: Artes Médicas, 2001.

FERREIRO E.; TEBEROSKY, A. Psicogênese da língua escrita. Porto Alegre: Artmed, 1999.

FONSECA, V. da. Dislexia, cognição e aprendizagem: uma abordagem neuropsicológica das dificuldades de aprendizagem da leitura. Rev. Psicopedagogia. São Paulo, v. 26, n.81, p. 339356. Disponível em: http://pepsic.bvsalud.org/pdf/psicoped/v26n81/v26n81a02.pdf. Acesso em: 22 nov. 2019.

FURTADO, V. Q. Uma intervenção psicopedagógica via jogos de regras. 3.ed. Petrópolis, RJ: Vozes, 2012.

GARCIA, J.-N. Manual de dificuldades de aprendizagem: linguagem, leitura, escrita e matemática. Porto Alegre: Artmed, 1998. .

GIL, A. C. Como elaborar projetos de pesquisa. 5.ed. São Paulo: Atlas, 2010.

GOMES, M. de F. C. Dificuldades de aprendizagem na alfabetização. 3.ed. Belo Horizonte: Autêntica/Ceale, 2011.

GOULART, C. M. A. Como alfabetizar? Na roda dos professores dos anos iniciais. São Paulo: Papirus, 2016.

InfoCEEDI. Sobre Crianças com Dislexia definimos. Boletim do Centro de Estudos, Documentação, Informação sobre a Criança do Instituto de Apoio à Criança. Largo da 
Memória, Lisboa, n. 32. 2011. Disponível em:

http://www.appdae.net/documentos/informativos/infocedi_dislexia.pdf. Acesso em: 22 nov. 2019.

INSTITUTO ABCD. Perguntas e respostas. Disponível em:

http://www.institutoabcd.org.br/perguntaserespostas/. Acesso em: 22 nov. 2020.

LEITE, S. A. S. A afetividade no processo de constituição do leitor. Atos de pesquisa em educação - PPGE/ME FURB, v. 6, n.1, p. 25-52, jan./abr. 2011.

MASCARENHAS, S. A. Metodologia cientifica. 1.ed. São Paulo: Pearson Education no Brasil, 2012.

MICOTTI, M. C. de O. Leitura e escrita como aprender com êxito por meio da pedagogia de projetos. São Paulo: Contexto, 2009.

MOOJEN, S.; COSTA, A. C. Transtornos da aprendizagem: abordagem neurobiológica e multidisciplinar. Porto Alegre: Artmed, 2006.

MONTEIRO, D. C. Teoria e prática na formação de professores. Cadernos da Pedagogia, v.02, n.4, p.140-148, ago./dez., 2008.

NEGRINE, A. Aprendizagem e desenvolvimento infantil. Porto Alegre: Prodil, 1994.

NOGUEIRA, M. O. G. Dificuldades de aprendizagem: um olhar psicopedagógico. Curitiba: InterSaberes, 2012.

OLIVEIRA, W. D.; MONTEIRO, D.C Alfabetizar para incluir. Revista UNIARA. Araraquara, v. 21/22.p.176-187, 2009.

PAÍN, S. Diagnóstico e tratamento dos problemas de aprendizagem. Porto Alegre: Artmed, 1985.

PINTO, K. de M.; MENEZES, C. Ri. Aprendizagens no enlace de desejo: (des)coberta na autoria. In: PAIM, R. M. de O.; FOLBERG, Ma. N. Ler ou não ler: drama ou desafio? Porto Alegre: Letra e Vida, 2013.

RIEF, S.; HEIMBURGE, J. Como ensinar todos os alunos na sala de aula inclusiva: estratégias prontas a usar, lições e atividades concebidas para ensinar alunos com necessidades educativas especiais de aprendizagem diversas Porto: Porto Editora, 2000.

SILVA, E. T. Partilha e conflito de interpretações: um caminho para o desenvolvimento da linguagem do leitor infantil. In: SMOLKA, A. L. B.; SILVA; E. T.; ZILBERMAN, R. Leitura e desenvolvimento da linguagem. Campinas: ALB, 2010.

SOARES, M. Alfabetização e letramento. 7.ed. São Paulo: contexto, 2017.

TORRES, R.; FERNÁNDEZ, P. Dislexia, Disortografia e Disgrafia. Amadora: McGrawHill, 2001. 
VALMASEDA, M. Os problemas de linguagem na escola. In: COLL, C; PALACIOS, J.; MARCHESI, A. (Org.). Desenvolvimento psicológico e educação: necessidades educativas especiais e aprendizagem escolar. 3.ed. Porto Alegre: Artes Médicas, 2007.

WEISS, M. L. L. Psicopedagogia clínica: uma visão diagnóstica dos problemas de aprendizagem escolar. 14.ed. Rio de Janeiro: Lamparina, 2012. 